Cross-sectional prevalence of helminth infections in cattle on traditional, small-scale and large-scale dairy farms in Iringa District, Tanzania

Keyyu, J.D.; Kassuku, A.A.; Msalilwa, L.P.; Monrad, Jesper; Kyvsgaard, Niels Chr.

Published in:

Veterinary Research Communications

DOI:

10.1007/s11259-005-3176-1

Publication date:

2006

Document version

Publisher's PDF, also known as Version of record

Citation for published version (APA):

Keyyu, J. D., Kassuku, A. A., Msalilwa, L. P., Monrad, J., \& Kyvsgaard, N. C. (2006). Cross-sectional prevalence of helminth infections in cattle on traditional, small-scale and large-scale dairy farms in Iringa District, Tanzania. Veterinary Research Communications, 30(1), 45-55. https://doi.org/10.1007/s11259-005-3176-1 


\title{
Cross-sectional Prevalence of Helminth Infections in Cattle on Traditional, Small-scale and Large-scale Dairy Farms in Iringa District, Tanzania
}

\author{
J.D. Keyyu ${ }^{1,2}$, A.A. Kassuku², L.P. Msalilwa ${ }^{2}$, J. Monrad ${ }^{3}$ and N.C. Kyvsgaard ${ }^{4}$ \\ ${ }^{1,2}$ Tanzania Wildlife Research Institute, PO Box 661, Arusha, Tanzania; ${ }^{2}$ Department of \\ Veterinary Microbiology and Parasitology, Sokoine University of Agriculture, Morogoro, \\ Tanzania, ${ }^{3}$ Danish Centre for Experimental Parasitology, ${ }^{4}$ Department of Animal Science \\ and Animal Health, The Royal Veterinary and Agricultural University, Frederiksberg C, \\ Denmark \\ *Correspondence: E-mail: keyyu@yahoo.com
}

Keyyu, J.D., Kassuku, A.A., Msalilwa, L.P., Monrad, J. and Kyvsgaard, N.C., 2006. Cross-sectional prevalence of helminth infections in cattle on traditional, small-scale and large-scale dairy farms in Iringa district, Tanzania. Veterinary Research Communications, 30(1), 45-55

\section{ABSTRACT}

\begin{abstract}
A cross-sectional study was carried out to determine the prevalence of gastrointestinal (GI) nematodes and flukes (Fasciola and amphistomes) infection in communally grazed traditional cattle, zero-grazed small-scale dairy cattle and intensively grazed large-scale dairy cattle through examination of helminth eggs in faeces. Results indicated that the type of management, especially the grazing habit, has a significant influence on the prevalence and intensity of GI nematodes and flukes. The prevalence of GI nematodes in traditional, large-scale dairy and small-scale dairy cattle was $67 \%, 44.4 \%$ and $37 \%$, respectively, with the highest faecal egg counts in calves. The overall prevalence of Fasciola gigantica in traditional, large-scale dairy and small-scale dairy cattle was $63.8 \%, 46.2 \%$ and $28.4 \%$, respectively. The prevalence of amphistomes was $81.9 \%, 55.5 \%$ and $41.1 \%$ in traditional, large-scale dairy and smallscale dairy cattle, respectively. The high prevalence of flukes in the traditional system was attributed to communal grazing and watering management practices. Stomach flukes recovered in examined cattle at the abattoir were Calicophoron microbothrium and Cotylophoron jacksoni. About $42.1 \%$ of infected animals had both Fasciola and amphistomes. The prevalence of both GI nematodes and flukes varied greatly among villages and farms. The prevalence of both Fasciola and amphistomes was higher in adults $(58.5 \%, 75.2 \%)$ than in yearlings $(36.5 \%, 51.5 \%)$ or calves $(24.9 \%, 47.2 \%)$. The variation in the prevalence of both GI nematodes and flukes among management and age groups within systems can be used as an entry point towards rational use of anthelmintics for each management system. More studies on seasonal transmission pattern of all these parasites are required in order to design rational, economic and locally sustainable parasite control programmes.
\end{abstract}

Keywords: amphistome, helminths, management system, nematodes, Tanzania, trematodes

Abbreviations: df, degrees of freedom; epg, eggs per gram; FEC, faecal egg count; GI, gastrointestinal

\section{INTRODUCTION}

Helminth infections are an important cause of lost productivity in livestock worldwide, often necessitating anthelmintic treatment (Vercruysse and Claerebout, 2001). The southern highlands of Tanzania, especially Iringa district, are known to be a liver fluke 
endemic area (Mahlau, 1970; Makundi, 2001) and gastrointestinal (GI) nematodes are highly prevalent in traditional nomadic cattle (Keyyu et al., 2003a). A questionnaire survey conducted in the district indicated that farmers ranked helminthosis (worm infection) as the second most important disease in cattle after East Coast fever (ECF) in all management systems (Keyyu et al., 2003b). The cool and subhumid climate in the southern highlands of Tanzania provides optimum conditions for development and survival of free-living stages of GI nematodes, and there are numerous habitats for snails that are intermediate hosts for flukes. Reports from meat inspectors in the district have shown an increasing number of liver condemnations at abattoirs, reaching $100 \%$ condemnation in some villages (J.D. Keyyu, personal observation). In 2001, an outbreak of acute fasciolosis occurred in sheep at Amani dairy farm and caused 33\% mortality (Nsengwa et al., 2001).

The prevalence of Fasciola gigantica has been well documented in a number of countries in tropical Africa (Ogunrinade and Ogunrinade, 1980; Tembely et al., 1988). Reports of $F$. gigantica in Tanzania were documented some years ago in the Lake Victoria zone, Northern Tanzania and the Southern Highlands (Hammond, 1965). However, most of these studies were based on abattoir surveys, which rarely give precise data on the origin of the animals and most of those studies were characterized by poor experimental design, especially the sampling procedure. The study in Iringa by Mahlau (1970) involved only indigenous Zebu cattle under the traditional management system in the 'Great Ruaha Valley', while that of Makundi (2001) was conducted in only one village using tracers and could not give the prevalence in resident village cattle. For the past two decades, there has been an increasing diversity in cattle management systems in Tanzania and other developing countries as a way of subsidizing household income. Little is known about the prevalence of helminth infections among various cattle management systems. Moreover, despite some emphasis on rational use of anthelmintics based on management system (Barger, 1999), the interaction between management factors and parasitism is still poorly understood (Kassai, 1999) mainly owing to limited information on the helminth situation among management systems. This study aimed to determine the prevalence of helminth infections in three cattle management systems in Iringa district, Southern Highlands of Tanzania.

\section{MATERIALS AND METHODS}

\section{Study area}

The study was conducted in Iringa district (currently Iringa and Kilolo districts) of Iringa region in the Southern Highlands of Tanzania. The district has three main agroclimatic zones namely the lower plain (lowland zone), central plain (mid zone) and the highland zone (temperate plateau). The lowland zone lies at 900-1200 m above sea level and the annual rainfall is below $600 \mathrm{~mm}$; the mid zone lies at $1200-1600 \mathrm{~m}$ above sea level and the annual rainfall is $600-1000 \mathrm{~mm}$; the temperate plateau lies at 1600 $2700 \mathrm{~m}$ above sea level and the annual rainfall is $1000-1600 \mathrm{~mm}$. Vegetation cover in 
the lower plain is mainly thickets and scattered bushes. Derived savannah grasslands predominate in the mid zone, while typical rain forests are dominant in the highland zone. This study was conducted in the mid zone and the highland zone. The district has a unimodal rainfall; the rainy season is between December and May, while the dry season is between June and November. This study was conducted from February to March 2001.

\section{Cattle management systems}

The management systems investigated were large-scale dairy, small-scale dairy and traditional (indigenous) systems. The large-scale dairy farms had improved or semiimproved management systems. They had their own grazing land that was fenced or not fenced and animals were given concentrates, chopped grass and mineral supplementation. The common breeds were Ayrshire and Friesian and their crosses. Small-scale dairy system mainly involved zero-grazing with occasional semi-zero and tethering systems. In the former, the animals were permanently housed while those in the semi-zero system were housed during the rainy season and taken out for grazing during the dry season. The commonest feeding practice was the 'cut and carry system' whereby grasses were obtained by cutting from various places and carried for feeding the housed animals. Supplementation was very low, irregular and confined to milking cows. The common breeds were crosses of Ayrshire and Friesian with Boran or Zebu.

Traditional farms investigated were sedentary (stationary) herds where traditional farmers also practised agricultural activities. Animals were grazed and watered on communal areas during the day and housed around households in open kraals or 'bomas' at night. The indigenous breed, the Tanzania Short Horn Zebu (TSHZ, Iringa red ecotype) was the only breed on all traditional farms. Traditional cattle were denied of any form of modern animal husbandry such as supplementation, effective disease control, etc.

\section{Study design, sampling and selection of farms}

The design was a cross-sectional observational study conducted in the highland and the mid zones. A multi-stage stratified random sampling method was used to select animals from zones, villages, management systems, farms and age groups. Farms in each zone/village were categorized into large-scale dairy, small-scale dairy and traditional farms on the basis of the management system, especially the grazing/ feeding habit. Furthermore, animals in each farm were stratified into three age groups: calves ( $<8$ months), weaners/yearlings ( $8-24$ months) and adults ( $>24$ months). The study was carried out in four large-scale dairy farms and five villages (three in the highland zone and two in the mid zone). The selected villages were those that had both small-scale dairy and traditional farms and were within a one-day return field trip from the Iringa municipality (63 $\mathrm{km}$ radius). At least two traditional and five small-scale dairy farms were selected in each village. 
A total of 236 animals in large-scale dairy farms, 127 in small-scale dairy farms and 150 in traditional farms were sampled during the study (513 overall). At least 30 animals were randomly sampled in each large-scale dairy farm, a minimum of 10 animals in each traditional farm and a maximum of 5 animals in each small-scale dairy farm. For this study, a farm was defined as any establishment with a minimum of one animal.

\section{Samples and sample processing}

Faecal samples were taken for determination of the presence of Fasciola and/or amphistome eggs and for quantitative determination of nematode eggs. The number of nematode eggs per gram of faeces (epg) was used as an indirect measure of worm burden in animals. Faecal samples were collected per rectum using gloved fingers. The collected samples were labelled and placed in cool boxes and transported to the Veterinary Investigation Centre (VIC) in Iringa for examination. The presence of fluke eggs was determined by the sedimentation technique (Hansen and Perry, 1994). The number of eggs per gram of faeces for GI nematodes was determined by the modified McMaster method (MAFF, 1986). All samples collected were examined within $36 \mathrm{~h}$. Faecal samples that remained were pooled by management system and cultured for recovery of third-stage larvae $\left(\mathrm{L}_{3}\right)$ of nematodes as described by Hansen and Perry (1994). The $\mathrm{L}_{3}$ recovered were identified to genus level on the basis of length and morphology using identification keys. Moreover, 16 infected traditional Zebu cattle slaughtered at the regional abattoir were randomly selected and flukes were collected for identification of species infecting cattle.

\section{Data analysis}

Data was entered, validated, cleaned in a database and then imported into Statistix for Windows (Statistix, 1994) for analysis. Faecal egg counts (FECs) between management systems, village and age groups was analysed by one-way analysis of variance based on logarithmically transformed faecal egg counts $[\log (\mathrm{FEC}+25)]$. Pairwise comparison of means was carried using the least significant difference (LSD). FECs between sex and zones were analysed by two-sample $t$-test. The proportion of animals excreting Fasciola and/or amphistome eggs in faeces by management system, village, age, sex and zone was analysed using the chi square $\left(\chi^{2}\right)$ test. The risk of an animal being infected was analysed by SAS logistic regression (SAS, 1990). The overall level of significance in all analyses was $p<0.05$. 


\section{RESULTS}

\section{Prevalence of Fasciola and amphistomes}

The only liver fluke species recovered was Fasciola gigantica while Calicophoron microbothrium and Cotylophoron jacksoni were the only stomach flukes recovered from the 16 traditional Zebu cattle examined at the abattoir. The prevalence of Fasciola gigantica among management systems is shown in Table I. Management system was found to have significant association with the prevalence $\left(\chi^{2}=30.52\right.$, $\mathrm{df}=$ $2, p=0.0001)$ as traditional cattle had significantly higher risk of infection than both small-scale $(p=0.02)$ and large-scale $(p=0.008)$ dairy cattle. The prevalence of amphistomes among management systems is shown in Table II. The prevalence of amphistomes was associated to the management system $\left(\chi^{2}=46.05\right.$, df $=2, p=$ $0.0001)$ and was highest in cattle under the traditional management system. The prevalence of amphistomes was always higher than that of Fasciola in all management systems, farms and villages. Out of 482 animals examined, 203 (42.1\%) were infected with both Fasciola and amphistomes. Concurrent infections were highest in the traditional management system and lowest in the small-scale dairy management system.

TABLE I

Prevalence of Fasciola gigantica among management systems in Iringa District

\begin{tabular}{lccc}
\hline & & \multicolumn{2}{c}{ Prevalence (\%) } \\
\cline { 3 - 4 } Management system & Animals examined & Mean & Range \\
\hline Large-scale dairy farms & 236 & $46.2^{\mathrm{a}}$ & $4-92$ \\
Small-scale dairy farms & 102 & $28.4^{\mathrm{b}}$ & $0-54$ \\
Traditional farms & 144 & $63.8^{\mathrm{c}}$ & $19-75$ \\
Overall & 482 & 46.1 & $0-92$ \\
\hline
\end{tabular}

${ }^{a, b, c}$ Values with different superscripts in a column are significantly different $(p<0.05)$

Both Fasciola and amphistomes were prevalent in all villages and farms surveyed, the prevalence varying greatly among villages and farms in the same management system. Ifunda village had the highest prevalence of both Fasciola $(73.2 \%)$ and amphistomes (79\%); Ilula village had the lowest prevalence of Fasciola (14.8\%), while Lulanzi village had the lowest prevalence of amphistomes $(59.6 \%)$. There was no significant difference $(p=0.91)$ in the prevalence of Fasciola between the highland zone $(47.5 \%)$ and mid zone $(48 \%)$; the prevalence of amphistomes also did not differ significantly between zones (60 vs $60.9 \%, p=0.84)$. 
TABLE II

Prevalence of amphistomes among management systems in Iringa district

\begin{tabular}{lccc}
\hline & & \multicolumn{2}{c}{ Prevalence (\%) } \\
\cline { 3 - 4 } Management system & Animals examined & Mean & Range \\
\hline Large-scale dairy farms & 236 & $55.5^{\mathrm{a}}$ & $4-100$ \\
Small-scale dairy farms & 102 & $41.1^{\mathrm{a}}$ & $0-83$ \\
Traditional farms & 144 & $81.9^{\mathrm{b}}$ & $67-92$ \\
Overall & 482 & 62.6 & $0-100$ \\
\hline
\end{tabular}

${ }^{\mathrm{a}, \mathrm{b}}$ Values with different superscripts in a column are significantly different $(p<0.05)$

TABLE III

Age-specific prevalence of Fasciola gigantica among management systems and age groups in Iringa District

\begin{tabular}{|c|c|c|c|c|c|c|}
\hline \multirow[b]{3}{*}{ Management system } & \multicolumn{6}{|c|}{ Age } \\
\hline & \multicolumn{2}{|r|}{ Adults } & \multicolumn{2}{|c|}{ Weaners/Yearlings } & \multicolumn{2}{|r|}{ Calves } \\
\hline & No. & $\begin{array}{c}\text { Prevalence } \\
(\%)\end{array}$ & No. & $\begin{array}{c}\text { Prevalence } \\
(\%)\end{array}$ & No. & $\begin{array}{c}\text { Prevalence } \\
(\%)\end{array}$ \\
\hline Large-scale dairy & 52 & $61.5^{\mathrm{a}}$ & 146 & $50^{\mathrm{a}}$ & 36 & $11^{\mathrm{a}}$ \\
\hline Small-scale dairy & 54 & $42.6^{\mathrm{b}}$ & 17 & $0^{\mathrm{b}}$ & 29 & $13.7^{\mathrm{a}}$ \\
\hline Traditional & 56 & $71.4^{\mathrm{c}}$ & 74 & $59.5^{\mathrm{a}}$ & 12 & $50^{\mathrm{b}}$ \\
\hline Total & 162 & 58.5 & 249 & 36.5 & 65 & 24.9 \\
\hline
\end{tabular}

${ }^{\mathrm{a}, \mathrm{b}}$ Values with different superscripts in a column are significantly different $(p<0.05)$

The age-specific prevalence of $F$. gigantica among management systems is shown in Table III. There was an association between age and prevalence in animals $\left(\chi^{2}=34.94\right.$, $\mathrm{df}=2, p=0.001)$. In all management systems, adults $(p=0.05)$ and weaners/yearlings $(p=0.042)$ had higher risk than calves. The age-specific prevalence of amphistomes among management systems is shown in Table IV. The prevalence of amphistomes among management systems was associated with the age of animal $\left(\chi^{2}=38.06, \mathrm{df}=2\right.$, $p=0.0001$ ). Adults had the highest prevalence, while calves had the lowest prevalence of amphistomes. There was no significant association between sex and prevalence of Fasciola $\left(\chi^{2}=0.64, \mathrm{df}=1, p=0.42\right)$ or amphistomes $\left(\chi^{2}=0.06, \mathrm{df}=1, p=0.81\right)$. 
TABLE IV

Age-specific prevalence of amphistomes among management systems and age groups in Iringa District

\begin{tabular}{|c|c|c|c|c|c|c|}
\hline \multirow[b]{3}{*}{ Management system } & \multicolumn{6}{|c|}{ Age } \\
\hline & \multicolumn{2}{|r|}{ Adults } & \multicolumn{2}{|c|}{ Weaners/Yearlings } & \multicolumn{2}{|r|}{ Calves } \\
\hline & No. & $\begin{array}{c}\text { Prevalence } \\
(\%)\end{array}$ & No. & $\begin{array}{c}\text { Prevalence } \\
(\%)\end{array}$ & No. & $\begin{array}{c}\text { Prevalence } \\
(\%)\end{array}$ \\
\hline Large-scale dairy & 52 & $76.9^{\mathrm{a}}$ & 146 & $55.5^{\mathrm{a}}$ & 36 & $27.7^{\mathrm{a}}$ \\
\hline Small-scale dairy & 54 & $59.3^{\mathrm{b}}$ & 29 & $23.5^{\mathrm{b}}$ & 29 & $13.8^{\mathrm{b}}$ \\
\hline Traditional & 56 & $89.3^{\mathrm{c}}$ & 74 & $75.6^{\mathrm{c}}$ & 12 & $100^{\mathrm{c}}$ \\
\hline Total & 162 & 75.2 & 249 & 51.5 & 65 & 47.2 \\
\hline
\end{tabular}

${ }^{\mathrm{a}, \mathrm{b}}$ Values with different superscripts in a column are significantly different $(p<0.05)$

\section{Gastrointestinal nematodes}

The prevalence, faecal egg counts, range and the proportion of animals with less than 500 epg among management systems are shown in Table V. The 500 epg cut-off point was selected based on salvage treatments for helminthosis in cattle in the District (Keyyu, 2004). There was a significant difference in FEC among management systems $(p=0.0001)$. Faecal egg counts were highest in the traditional system and lowest in the small-scale dairy system. There was a significant difference in FEC among age groups $(p=0.001)$. Calves had the highest FEC $(280 \pm 66 \mathrm{epg})$, weaners/yearlings were intermediate $(191 \pm 22 \mathrm{epg})$, and adults had the lowest FEC (78 $\pm 10 \mathrm{epg})$. Pairwise comparison of means indicated that FEC in calves and weaners/yearlings were not significantly different. There was no difference in FEC between male and female animals $(175 \pm 24$ vs $165 \pm 22, p=0.76)$. The intensity of infection did not differ between the highland and the lowland zones $(p=0.81)$. Faecal egg counts varied significantly among villages $(p=0.001)$, being highest at Ilula village $(607 \pm 167 \mathrm{epg})$ and lowest at Ifunda village (99 $\pm 17 \mathrm{epg})$. Overall, a high proportion $(89.8 \%)$ of animals had low FEC $(<500$ epg). Animals that had FEC $>500$ epg were mostly calves and weaners.

\section{Faecal culture}

The overall proportions of infective larvae from cultures among management systems indicated that the common GI nematodes were Cooperia spp. $(39.8 \%)$, Oesophagostomum spp. (35.9\%), Haemonchus spp. (21.6\%) and Trichostrongylus spp. (2.5\%). Other GI nematodes identified through egg morphology were Trichuris spp., 
TABLE V

Prevalence and intensity of GI nematodes and the proportion of animals with less than 500 epg among management systems

\begin{tabular}{lccccc}
\hline $\begin{array}{l}\text { Management } \\
\text { system }\end{array}$ & $\begin{array}{c}\text { Number } \\
\text { examined }\end{array}$ & $\begin{array}{c}\text { Prevalence } \\
(\%)\end{array}$ & $\begin{array}{c}\text { Mean } \\
\text { FEC } \pm \text { SE }\end{array}$ & Range & $\begin{array}{c}\text { Percentage } \\
\text { with FEC } \\
<500 \text { epg }\end{array}$ \\
\hline $\begin{array}{l}\text { Small-scale dairy } \\
\text { Large-scale dairy }\end{array}$ & 127 & $37^{\mathrm{a}}$ & $107 \pm 19^{\mathrm{a}}$ & $0-1200$ & 100 \\
Traditional farms & 150 & $444^{\mathrm{a}}$ & $117 \pm 14^{\mathrm{a}}$ & $0-1300$ & 94.4 \\
$\begin{array}{l}\text { Overall } \\
513\end{array}$ & $57^{\mathrm{b}}$ & $296 \pm 46^{\mathrm{b}}$ & $0-2900$ & 80 \\
& 50 & $167 \pm 16$ & $0-2900$ & 89.8 \\
\hline
\end{tabular}

${ }^{\mathrm{a}, \mathrm{b}}$ Values with different superscripts in a column are significantly different $(p<0.05)$

Capillaria spp. and Strongyloides spp. Haemonchus spp. were more often observed in cultures from dairy cattle while Oesophagostomum spp. were frequently observed in cultures from traditional cattle.

\section{DISCUSSION}

The study indicated a significant influence of management practices especially the grazing/feeding habit, on the prevalence of flukes and GI nematodes in cattle. Moreover, the study indicated a high prevalence and widespread distribution of flukes and a moderate prevalence and low intensity of GI nematodes. However, the fact that faecal samples were collected at the height of the rainy season might have increased the prevalence of GI nematodes and decreased the prevalence of flukes. The overall prevalence of Fasciola in traditional cattle $(63.8 \%)$ is higher than reported previously in indigenous Zebu cattle in Iringa (Mahlau, 1970) and Mbeya (Ecimovic and Mahlau, 1973) regions in the Southern Highlands of Tanzania. The high prevalence is in line with reports in other tropical countries (Ogambo-Ongoma, 1972; Silangwa, 1973; Schillhorn van Veen, 1980; Tembely et al., 1988; Heinonen et al., 1995). The high prevalence of flukes in a number of farms in the present study indicates that flukes in cattle are a growing problem in the Southern Highlands of Tanzania. The prevalence of flukes in the district may be higher than obtained in this study because some infected animals might have been missed by the sedimentation technique, which is characteristically poor in detection of fluke eggs.

The moderate to high overall prevalence of Fasciola (28.4\%) and amphistomes $(41.1 \%)$ in zero-grazed small-scale dairy cattle gives some indication for anthelmintic treatments in zero-grazed cattle especially those fed pastures from contaminated areas. The 'cut and carry' system of obtaining food from pastures from valleys grazed by traditional cattle during the dry season might have been responsible for infection of 
zero-grazed animals. Farmers should be educated on the importance of using personal pasture and dry season feed reserves as means to ensure safe feed for zero-grazed cattle. The high prevalence of flukes and GI nematodes in traditional cattle concurs with studies in other tropical countries (Kaufmann and Pfister, 1990; Anene et al., 1994; Moyo et al., 1996). The high prevalence might be a reflection of the management practices; dairy farms had improved management with routine anthelmintic treatments that may have reduced the prevalence and burdens compared to traditional farms. The high stocking density in communal grazing and watering areas might have facilitated pasture contamination and ingestion of infective stages by grazing traditionally managed cattle.

The study has indicated a high prevalence of amphistomes in grazing animals. The higher prevalence of amphistomes than of Fasciola concurs with other studies (Nyundo, 1994; Szmidt-Adjidé et al., 2000; Mage et al., 2002). The high prevalence may be due to the high biological potential of the intermediate snail host (Dinnik, 1964), the direction of control measures mainly against Fasciola and GI nematodes, and the lack of effective drugs against amphistomes (Mage et al., 2002). The higher prevalence of flukes in adults than young animals concurs with other studies (Mahlau, 1970; Silangwa, 1973; Schillhorn van Veen, 1980) and may be related to longer exposure time during the animals' life for adults (cumulative infections with age). It may also be due to the fact that adults rarely receive routine anthelmintic treatments in traditional farms (Keyyu et al., 2003b). Furthermore, it may be related to the management system, whereby calves grazed around farms whereas adults were trekked long distances to valleys, flood plains or swampy areas during the dry season, so exposing adults to metacercariae-contaminated pastures.

All the nematode parasites recovered in faecal cultures have been reported previously in Tanzania (Ecimovic and Mahlau, 1973; Mellau, 1997) and in other tropical countries (Moyo et al., 1996; Waruiru et al., 2001) where Haemonchus spp. or Cooperia spp. were the main genera. The study has indicated that most adults and weanlings had FECs below the cut off point of $500 \mathrm{epg}$ for salvage anthelmintic treatments (Keyyu, 2004). The low FEC, especially in adult cattle, concurs with other studies (Stuedemann et al., 1989; Couvillion et al., 1996; Nodtvedt et al., 2002). The higher FEC in calves than adults concurs with other studies (Snyder, 1993; Anene et al., 1994). The high FEC in calves might be due to limited previous exposure and immaturity of the immune system resulting in a large proportion of ingested larvae developing into adults.

In conclusion, the study clearly indicates that control measures should make use of the variation in helminth prevalence and intensity among management systems and age groups within management systems to achieve rational use of anthelmintics. Also, the study indicates a need for specific extension messages in each management system, as opposed to farmers with different management practices being given similar messages with regard to anthelmintic treatments. Further studies on seasonal transmission patterns of flukes and GI nematodes among management systems are required for the design of affordable and cost-effective worm control programmes at community level. 


\section{ACKNOWLEDGEMENT}

The authors are grateful to the District Agricultural and Livestock Development Officer (DALDO), Division extension officers, village extension officers and farmers in Iringa district for their kindness and cooperation during this study. We acknowledge the field and technical assistance from Msr L.P. Msalilwa, D. Mwangoka, A. Manyesela, Rehani Ahmadi, J. Mwesongo, K. Yowela, D. Tukunjoba, and Ms Janet Longo. Members of staff at the Veterinary Investigation Centre (VIC) in Iringa are highly acknowledged for their valuable cooperation. This study was wholly sponsored by DANIDA (ENRECA programme) through the Livestock Helminths Research Project (LHRP) at Sokoine University of Agriculture. This financial support is highly appreciated.

\section{REFERENCES}

Anene, B.M, Onyekwodiri, E.O., Chime, A.B. and Anika, S.M. 1994. A survey of gastrointestinal parasites in cattle in Southeast Nigeria. Preventive Veterinary Medicine, 20, 297-306

Barger, I.A., 1999. The role of epidemiological knowledge and grazing management for helminth control in small ruminants. International Journal for Parasitology, 29, 41-47

Couvillion, C.E., Siefker, C. and Evans, R.R., 1996. Epidemiological study of nematode infections in a grazing beef cow-calf herd in Mississippi. Veterinary Parasitology, 64, 207-218

Dinnik, J.A., 1964. Intestinal paramphistomiasis and Calicophoron microbothrium Fischoeder in Africa. Bulletin of Epizootic Diseases in Africa, 12, 439-454

Ecimovic, T.J. and Mahlau, E.A., 1973. Animal Health Survey in cattle in Mbeya Region of Tanzania. Bulletin of Epizootic Diseases in Africa, 21, 187-192

Hammond, J.A., 1965. Observations of fascioliasis in Tanganyika. Bulletin of Epizootic Diseases in Africa, $13,55-65$

Hansen, J. and Perry, B., 1994. The Epidemiology, Diagnosis and Control of Helminth Parasites of Ruminants. A Handbook, (ILRAD) Nairobi, Kenya, 171

Heinonen, M., Rufe, G. and Kabede, S., 1995. The effect of anti-parasitic treatment against Fasciola on crossbred and Zebu cows in Ethiopia. War/RMS, 82, 90-92

Kassai, T., 1999. Veterinary Helminthology, (Butterworth-Heinemann, Oxford)

Kaufmann, J. and Pfister, K., 1990. The seasonal epidemiology of gastrointestinal nematodes in N'dama cattle in the Gambia. Veterinary Parasitology, 37, 45-54

Keyyu, J.D., 2004. Epidemiology and control of worm infections in cattle on traditional, small-scale and largescale dairy farms in Iringa district, Tanzania, (PhD thesis, Sokoine University of Agriculture, Morogoro, Tanzania)

Keyyu, J.D., Kassuku, A.A., Kyvsgaard, N.C. and Willingham, A.L., 2003a. Gastrointestinal nematodes in indigenous Zebu cattle under pastoral and nomadic management systems in the lower plain of the Southern Highlands of Tanzania. Veterinary Research Communications, 27, 371-380

Keyyu, J.D. Kyvsgaard, N.C., Kassuku, A.A. and Willingham, A.L., 2003b. Worm control practices and anthelmintic usage in traditional and dairy cattle farms in the Southern highlands of Tanzania. Veterinary Parasitology, 114, 51-61

MAFF (Ministry of Agriculture, Fisheries and Food), 1986. Manual of Parasitological Laboratory Techniques, Reference book number 418, 3rd edn, (HMSO, London)

Mage, C., Bourgne, H., Toullien, J.M., Rondelaud, D. and Dreyfuss, G., 2002. Fasciola hepatica and Paramphistomum daubneyi: changes in prevalences of natural infections in cattle and in Lymnaea truncatula from central France over 12 years. Veterinary Research, 33, 439-447

Mahlau, E.A., 1970. Liver fluke survey in Zebu cattle of Iringa region of Tanzania and the first finding of the small fluke Dicrocoelium hospes /Loos. Bulletin of Epizootic Diseases in Africa, 18, 21-28

Makundi, A.E., 2001. Epidemiology and control of bovine fasciolosis and schistosomosis in Tanzania, $\mathrm{PhD}$ thesis, Sokoine University of Agriculture, Morogoro, Tanzania) 
Mellau, L.B.S., 1997 Factors associated with diseases and mortality of calves in Morogoro, (Dissertation submitted in partial fulfilment for the degree of Master of Veterinary Medicine (MVM), Sokoine University of Agriculture, Morogoro, Tanzania)

Moyo, D.Z., Bwangamoi, O., Hendrix, W.M.L. and Eysker, M., 1996. The epidemiology of gastrointestinal nematode infections in communal cattle and commercial beef cattle on the highveld of Zimbabwe. Veterinary Parasitology, 67, 105-120

Nodtvedt, A., Dohoo, I., Sanchez, J., Conboy, G., DesCjteaux, L., Keefe, G., Leslie, K. and Campbell, J., 2002. The use of negative binomial modeling in a longitudinal study of gastrointestinal parasite burdens in Canadian dairy cows. Canadian Journal of Veterinary Research, 66, 249-457

Nsengwa, G.R.M., Dulle, C.K., Keyyu, J.D. and Kassuku, A.A., 2001. An outbreak of acute fasciolosis confined to sheep in a farm in Iringa. Case report. In: Proceedings of the 17th Tanzania Veterinary Association (TVA) Scientific Conference, (AICC, Arusha, Tanzania), 18

Nyundo, B.A., 1994. Studies on amphistomes of domestic ruminants in Kasulu district, Tanzania, (MSc dissertation, University of Dar es Salaam, Tanzania)

Ogunrinade, A. and Ogunrinade, B.I., 1980. Economic importance of bovine fasciolosis in Nigeria. Tropical Animal Health and Production, 12, 155-160

Ogambo-Ongoma, A.H., 1972 Fasciolosis survey in Uganda. Bulletin of Epizootic Diseases in Africa, 20, $35-41$

SAS (Statistical Analysis System Institute Inc), 1990. Introductory Guide for Personal Computers, Release 6.03 Edition, (SAS Inc., Cary, NC)

Schillhorn van Veen, T.W., 1980. Fascioliasis (Fasciola gigantica) in West Africa: a review. Veterinary Bulletin, 50, 529-533

Silangwa, S.M., 1973. Incidence of liver flukes (Fasciola gigantica) in Barotse cattle, Zambia. Bulletin of Epizootic Diseases in Africa, 21, 11-17

Statistix, 1994. Statistix 4.1. Analytical Software. User's Manual, (Tallahassee, FL)

Stuedemann, J.A., Ciordia, H., Myers, G.H. and McCampbell, H.C., 1989. Effect of a single strategically timed dose of fenbendazole on cow and calf performance. Veterinary Parasitology, 34, 77-86

Snyder, D.E., 1993. Epidemiology of Ostertagia ostertagi in cow-calf herds in the southeast United States. Veterinary Parasitology, 46, 277-288

Szmidt-Adjidé, V., Abrous, M., Adjidé, C.C. and Dreyfuss, G., 2000. Prevalence of Paramphistomum daubneyi infection in cattle. Veterinary Parasitology, 87, 133-138

Tembely, S., Galvin, T.J., Craig, T.M. and Traore, S., 1988. Liverfluke infections of cattle in Mali. An abattoir survey on prevalence and geographic distribution. Tropical Animal Health and Production, 20, $117-121$

Vercruysse, J. and Claerebout, E., 2001. Treatment vs. non-treatment of helminth infections in cattle: defining the thresholds. Veterinary Parasitology, 98, 195-214

Waruiru, R.M, Thamsborg, S.M., Nansen, P., Kyvsgaard, N.C., Bøgh, H.O., Munyua, W.K. and Gathuma, J.M., 2001 The epidemiology of gastrointestinal nematodes of dairy cattle in central Kenya. Tropical Animal Health and Production, 33, 173-187

(Accepted: 19 August 2004) 